\title{
Perception of male otolaryngologists on gender discrimination: a comparative study
}

\author{
İlknur Haberal Can ${ }^{1}$ (1) $\cdot$ Armağan İncesulu ${ }^{2} \cdot$ Hülya Eyigör ${ }^{3} \cdot$ Yeşim Şenol ${ }^{4}$. Cüneyt Orhan Kara ${ }^{5}$
}

Received: 29 June 2020 / Accepted: 4 September 2020 / Published online: 17 September 2020

c) Springer-Verlag GmbH Germany, part of Springer Nature 2020

\begin{abstract}
Purpose To gather information on perception of male otolaryngologists (MORLs) about gender discrimination towards female otolaryngologists (FORLs).

Methods MORLs were invited to participate to an online survey. Minimum participation requirement was completion of at least their first year of residency. The responses were analyzed and compared vis-a-vis with the previously conducted similar survey among FORLs.

Results Statistically significant responses on the Likert scale are classified in four main groups. MORLs and FORLs share the same views about financial factors, benefits and opportunities, housework as burden, establishing work-life balance and physical strength requirements. They have opposing views about FORLs being meticulous, exposed to more negative attitude of the opposite gender and men's dominance in decision-making. FORLs don't have consensus, but MORLs disagree about MORLs being favored in pursuing academic careers. On the other hand, MORLs don't have consensus, but FORLs agree about patients having more confidence in MORLs.

Conclusion MORLs don't usually have any confrontation with FORLs in regards to the roles of women in the society such as their motherhood role. On the other hand, MORLs show rather a contradiction on their perception towards the gender discrimination mainly in achieving career goals by FORLs such as growing in the profession and holding managing roles. When the views of the both gender group are compared, MORLs don't seem to fully acknowledge FORLs' gender discrimination experience.
\end{abstract}

Keywords Gender discrimination · Gender inequality · Otolaryngology $\cdot$ Female otolaryngologist $\cdot$ Male otolaryngologist

İlknur Haberal Can

haberalcan@gmail.com

1 Otolaryngology Head and Neck Surgery, Yozgat Bozok University Medical Faculty, Yozgat, Turkey

2 Otolaryngology Head and Neck Surgery, Eskişehir Osmangazi University Medical Faculty, Eskişehir, Turkey

3 Otolaryngology Head and Neck Surgery, Sağlık Bilimleri University Antalya Training and Research Hospital, Antalya, Turkey

4 Department of Medical Education, Antalya University Medical Faculty, Antalya, Turkey

5 Otolaryngology Head and Neck Surgery, Denizli Pamukkale University Medical Faculty, Denizli, Turkey

\section{Introduction}

Equal opportunities and representation of all genders in the work force are very important. This is of course not an exception in the medical society. Otolaryngology has been one of the male-dominant surgical branches in Turkey. According to the numbers given at the official website of Turkish Otolaryngology Head and Neck Society, number of male specialists is approximately eight times higher than that of female specialists.

Gender equality in medicine may lead to significant benefits in healthcare system [1]. Gender equality among employees creates a better environment both for staff and patients. Moreover, gender-diversed workplace increases productivity, innovation, decision-making, and work satisfaction. In such environment, the workforce better understands the needs of both genders. Besides, the patients may prefer to be treated by a specific gendered doctor [1]. The different 
approaches for patient treatments by male and female doctors may develop mutual interaction as role models.

Gender discrimination means unequal treatment to a person depending on his or her gender. This unequal treatment may be about proportions, wages, hiring process and laying off, decision-making positions, leadership, giving birth, training, and education. In our previously conducted study, the female otolaryngologists (FORLs) claimed the presence of gender discrimination mainly in salary, academic career, work-life balance, representation in leadership and administrative positions, and promotions [2]. The purpose of this study is to gather information about the perceptions of gender discrimination among the male otolaryngologists (MORLs) and their opinions towards gender discrimination.

\section{Materials and methods}

An online survey of 46 questions, both close ended and on the 5-point Likert scale, was prepared to obtain MORLs' feedback about gender discrimination. Upon the approval of this study by the Clinical Research Ethics Committee of Yozgat Bozok University (2017-KAEK-189_2020.02.26_03), a group of ten male residents and specialists who received postgraduate education in the field of otolaryngology was selected to fill the survey to test its validity and clarity of the questions. Besides collecting demographic data, the questions about the following topics were queried:

1. MORLs' thoughts about FORLs in general;

2. MORLs' gender preference as their co-workers;

3. MORLs' thoughts about FORLs' suitability for administrative positions;

4. working with female academics or colleagues during residency and afterwards;

5. MORLs' thoughts about their female colleagues' pregnancy and their maternity leave during residency or afterwards;

6. other medical branches suitable for female colleagues if otolaryngology is not a good fit for them;

7. MORLs' experience about any kind of discrimination, either negative or positive, against female colleagues;

8. MORLs' thoughts about inequality on salary, research related issues, lack of role model, work-life balance, promotions, etc.

9. exposure to any psychological pressure from FORLs because of their male gender.

The online survey was sent out by a Turkey-based ENT forum which is the largest forum to bring otolaryngologists, audiologists, and speech pathologists together. Only MORLs (academicians and non-academicians working at both private and public hospitals) and male residents who at least completed their first year of residency were eligible to participate to this survey. The total number of MORLs was 1574 according to membership roaster of the forum. Only 161 MORLs completed the online survey within 3 months during March-May 2020 under the unfavorable conditions of COVID-19 pandemic. During this data collection period, weekly reminders were regularly sent to the forum members to increase the participation. Answering to all survey questions was made mandatory for cross validation of the responses. Then, the responses were compared with those of FORLs on a 5-point Likert scale.

\section{Statistical analysis}

Chi square method of the SSPS 18 is used for statistical analysis. $P<0.05$ significance level is accepted as statistically significant.

\section{Results}

Distribution of the age groups are as follows; $16.1 \%$ 25-30, $34.2 \%$ 31-40, 20.5\% 41-50, 19.9\% 51-60, 6.8\% 61-70 and $2.5 \%$ above 70 .

The results are summarized in Tables 1, 2 .

\section{Marital status}

$65.8 \%$ of the respondents are married with working wives. $16.1 \%$ of them are married with housewives, $4.3 \%$ single and $3.7 \%$ divorced. $25.5 \%$ has no children, $31.7 \%$ one child, $36 \%$ two, $6.2 \%$ three, $0.6 \%$ four or more.

\section{Institutions, titles, and experience}

$40.4 \%$ of the participants completed their residency at a training and research hospital, $57.1 \%$ at a state university and $2.5 \%$ at a private university.

$15.5 \%$ of the participants are residents, $9.9 \%$ assistant professors, $6.7 \%$ associate professor, $14.3 \%$ professors, $12.4 \%$ instructors at training and research hospitals and the remaining is nonacademic MORLs. $43.3 \%$ of them occupies an academic position.

$21.7 \%$ of MORLs has less than 5 year experience in the field of otolaryngology, 13\% 5-10 years, 20.5\% 10-20 years, $29.2 \%$ more than 20 years at the time surveying. $15.5 \%$ of them are residents.

\section{Maternity leave and breastfeeding breaks}

8.7\% of MORLs has positive opinion towards FORLs having a child during their residency; $24.2 \%$ approves FORLs to 
Table 1 Distribution of MORLs' views on selected questions

\begin{tabular}{llll}
\hline & Yes & No & Neutral \\
\hline Women are suitable for otolaryngology & 85.1 & 14.9 & n/a \\
FORLs are eligible for otolaryngologic society administration & 67.1 & 1.9 & 31.1 \\
FORLs are eligibility for administrative roles & 65.2 & 13 & 21.7 \\
Positive gender discrimination exists towards FORLs & 49.1 & 44.1 & 6.8 \\
Negative gender discrimination exists towards FORLs & 14.3 & 83.2 & 2.5 \\
MORLs' willingness to work under a female administrator & 9.3 & 90.7 & n/a \\
& Men & Women & Neutral \\
Department head should be & 24.8 & 1.2 & 73.9 \\
MORLs are willing to work with & 42.9 & 3.7 & 53.4 \\
& Residency & & Neutral \\
MORLs view for timing of pregnancy & During & After & \\
& 6.8 & 24.8 & 68.3 \\
3 month maternity leave & Positive & Negative & Neutral \\
2 year unpaid maternity leave & 82 & 8.1 & 9.9 \\
\hline
\end{tabular}

have a child after residency and $67.1 \%$ is neutral about such specific timing. While $82 \%$ has positive opinion about the 3 month maternity leave during residency, $8.1 \%$ has negative opinion and $9.9 \%$ is neutral about it. Additionally, $63.4 \%$ is positive about FORLs taking 2 year unpaid leave after giving birth in post-residency, whereas $16.1 \%$ isn't in favor of such long leave and $20.5 \%$ is neutral.

\section{Work life}

$85.1 \%$ of MORLs states that otolaryngology is a suitable medical branch for female doctors. The remaining $14.9 \%$ states non-surgical clinical branches $(56.7 \%)$, basic sciences $(40 \%)$ and other surgical branches $(3.3 \%)$ are more suitable for female doctors.

$26.7 \%$ of MORLs worked with only one female resident or none during their residency, $27.3 \%$ with two, $16.1 \%$ with three and $29.8 \%$ with four or more. $9.3 \%$ of participants worked under a female administrator, i.e. a department head or an academic advisor during their residency. 59.6\% worked with FORLs in academic careers.

$65.2 \%$ thinks that FORLs are eligible for administrative positions, whereas $13 \%$ finds them ineligible, and the remaining $21.7 \%$ are neutral about it. However, only $3.7 \%$ is willing to work under a female administrator, and $42.9 \%$ prefers to work with a male administrator while $53.4 \%$ is neutral. Even though the majority of MORLs (73.9\%) thinks gender doesn't matter to be eligible for a department head or academic advisor, $1.2 \%$ of them thinks a female could fulfill those roles, and $24.8 \%$ thinks a male is eligible. $67.1 \%$ accepts FORLs as eligible for administrative positions in professional societies. $1.9 \%$ doesn't find their female colleagues eligible for such roles.
$64 \%$ of MORLs states gender does not offer any advantage in the field of otolaryngology, whereas $18.6 \%$ considers being a male is advantageous and $17.4 \%$ sees females having a gender-based advantage. $84.5 \%$ thinks FORLs don't necessarily have to work harder than their male colleagues, whereas $9.3 \%$ agrees that FORLs have to work much harder.

95\% of MORLs declares that they never felt any psychological pressure directly from their female administrators while working under them. 9.3\% of MORLs claims that they have been bullied by their female colleagues who don't hold any administrative positions.

\section{Gender discrimination}

$83.2 \%$ of the participants doesn't claim witnessing any kind of negative gender discrimination against FORLs, whereas $14.3 \%$ admits witnessing it. $2.5 \%$ doesn't have any idea about negative gender discrimination. While $49.1 \%$ claims that there is positive gender discrimination against FORLs, $44.1 \%$ disagrees about it.

$53.4 \%$ of MORLs states there is not any negative gender discrimination against FORLs when asked about their view on whom they see responsible for it. The remaining $46.6 \%$ believes there is discrimination, and they attribute such discrimination done by patients by $18.6 \%$, female colleagues by $14.3 \%$, male associates by $6.8 \%$ and their superiors by $6.8 \%$. Based on our previous survey [2], gender discrimination against FORLs was committed mainly, in descending order, by senior MORLs, colleagues, patients and hospital staff.

$70.2 \%$ of MORLs responds that there is no gender discrimination when asked about which areas they think FORLs are exposed to gender discrimination. The distribution of remaining answers is as follows: $19.3 \%$ family responsibilities, $8.1 \%$ performing lesser number of operations, $5.6 \%$ 


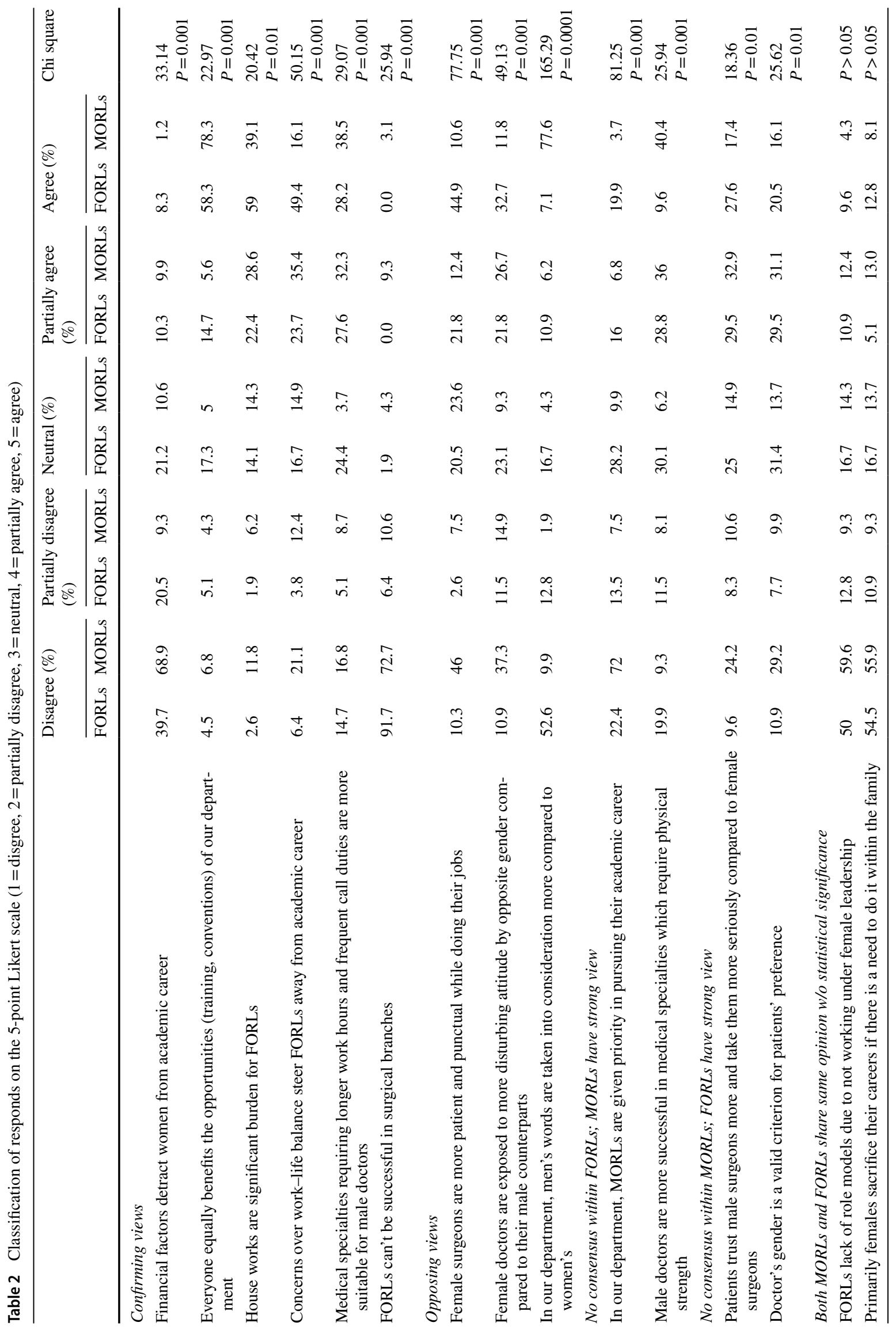


being allowed to attend scientific meetings, $2.5 \%$ examining higher number of patients daily. MORLs think there is no discrimination at all on the income level. Similarly, 94.4\% also confirms nonexistence of income inequality when asked directly with a follow-up question.

88.2\% of MORLs states FORLs' academic career is not deterred based solely on their gender. $71.4 \%$ also states FORLs' promotions are not gender dependent. Nearly $20 \%$ thinks that FORLs use their gender in their advantage for academic promotions.

The responses to the 13 questions on the 5-point Likert scale were found statistically significant. The responses in regards to 1) FORLs lack role models due to not working under female leadership, 2) primarily females sacrifice their careers if there is a need to do it within the family, not found statistically significant $(p>0.05)$. The results are tabulated in Table 2.

\section{Discussion}

Gender-related studies about females are generally done with exclusion of the opinions of males. Similarly, our previous study was conducted among FORLs [2] to document the female's perception of gender discrimination. Therefore, to diminish the bias, this survey is conducted as a follow-up study using the same methodology among MORLs. Even though MORLs outnumber FORLs in Otolaryngology, unfortunately the participation rate to this follow-up study stayed at $10.2 \%$.

In parallel to increasing number of women in otolaryngology over the past few decades, academic productivity gap has been closing between the both genders. However, gender discrimination against females in various aspects still persists [3]. The discrimination may be in different forms, for example, marginalization of female residents; FORLs being assigned to more work compared to their MORLs counterparts on the same seniority level, but to lesser number of operations; unfavorable working conditions; facing difficulties for maternity leaves, breastfeeding breaks and in pursuing an academic career; being seen as having less physical strength and capability; patients' preference for male surgeons and patients' less respectful attitudes towards female surgeons [2]. Such observations have also been documented in several previously published studies in surgical fields $[4,5]$.

The family medical leave act, short-term disability, and official vacation rights are used as basis for parental leave in the US. Some program directors still have negative attitudes towards maternity leave because of increased workload on co-residents on duty and delayed training of female residents during their maternity leaves [6]. In Turkey, the paid maternity leave is 13 weeks. Additionally, working mothers have an option for a long-term unpaid maternity leave up to 24 months. The majority of MORLs are very positive towards both short-term leave of 3 months by $93.4 \%$ and long term leave by $80 \%$. Despite to such high level of positive opinion, FORLs still claim they face challenges in using their maternity leave rights and the breastfeeding breaks [2]. The variation in perceptions between males and females may be due to MORLs being less sincere in their responses about such sensitive subject like motherhood.

Another discrepancy occurs in representations of FORLs by lesser numbers on the boards of otolaryngology associations even though MORLs support FORLs' assignments by $98 \%$ including the neutral responds. In reality, $85 \%$ of the administrative positions of the professional societies in the field of otolaryngology is held by MORLs. The dominance of MORLs in this respect is not the country specific issue. Number of females in such societies should be more balanced in an attempt to assure a gender diversity both in surgical branches and in subspecialties [7]. Additionally, the representation of females on the boards of societies and subsocieties should be constantly monitored as the number of senior female otolaryngologists increase overtime [8].

Perceptions of MORLs and FORLs on specific gender discrimination issues noticeably show a contrast. Even though $83 \%$ of MORLs claims that they didn't witness any negative gender discrimination towards FORLs, only 53.4\% of them actually thinks there is no gender discrimination at all when asked to collect their opinion on the same subject with a different question, "who do you think discriminate your female colleagues based on their gender?" The replies to this indirect question is consistent with that of FORLs who experienced gender discrimination. In this case, 30\% of MORLs could probably witness gender discrimination towards their female colleagues but they may deny confessing it. Interestingly, MORLs mainly consider patients and female colleagues as part of the reason of negative discrimination towards FORLs who, in fact, point to their superiors and male colleagues responsible for negative discrimination towards themselves. Furthermore, MORLs think that FORLs are subject to negative discrimination, in the order of frequency, in the areas of family responsibilities, attendance to operations, attendance to conferences and examining higher number of patients daily. Interestingly, $49 \%$ of the MORLs claims there is positive gender discrimination towards FORLs, which is confirmed only by $5 \%$ of FORLs.

Even though some studies refer to a gender-based salary scale among otolaryngologists [9-11], some other studies don't report such income inequality $[12,13]$. Apparently, there is not any consensus about this subject. In our study, MORLs also don't assert the existence of such inequality. This perception may be explained with the fixed pay scale used in the public hospitals in Turkey. On the other hand, the 
wage gap could be due to performance-based salary system used especially in the private sector.

Another comparative study conducted among the nonmedical academicians in Spain and the UK demonstrated that women perceived more gender inequality in areas of invitation to conferences as speakers, receiving scientific awards, representation on editorial boards of scientific publications, receiving citations, invitation to be a reviewer, promotions and leadership positions, whereas men did not perceive such extensive discrimination [14]. Similarly, Handley et al. documented that men didn't admit the existence of gender bias in science as women did [15]. This is an indication of unwillingness of men to acknowledge it, and the results of this study also support this conclusion.

When the Likert scale responses of MORLs are classified and compared to those of FORLs (Table 2), statistically significant opposing views are observed for 1) finding female surgeons more patient and punctual while doing their jobs (Fig. 1,2) primarily taking men's words into consideration (Fig. 2, 3) FORLs being much more exposed to disturbing behaviors by the opposite gender. Regardless of MORLs don't agree by $46 \%$, there are evidences about female doctors being more meticulous in the literature $[16,17]$. In reference to the question, "men's words are taken into consideration more compared to women's words in my department", $77.6 \%$ of MORLs' "agree" responses may be interpreted as an indication of their perception about their dominance over FORLs in the workplace which is acknowledged by only $7 \%$ of FORLs. On contrary, 52.6\% of FORLs disagree that men' worlds are more valued in decision-making. On the other hand, MORLs' answers to follow-up cross-questioning about MORLs being prioritized in pursuing an academic career may show a contradiction where MORLs don't really accept such preeminence (Fig. 3).

Moreover, the majority of MORLs and FORLs mutually agree that the offerings of academic opportunities are not

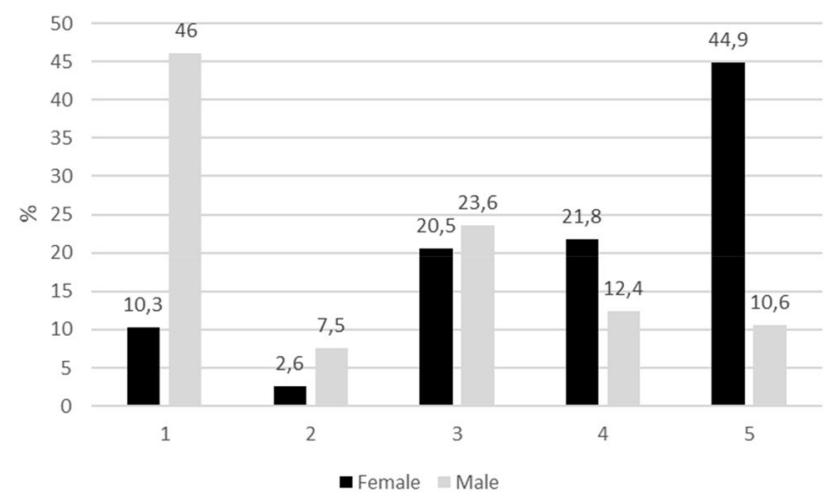

Fig. 1 Comparison of responses about finding female surgeons more patient and punctual while doing their jobs. Chi square: 77.75 $\mathrm{P}=0,001$. ( 1 = disagree, $2=$ partially disagree, $3=$ neutral, $4=$ partially agree, $5=$ agree) gender dependent. MORLs agree to it more by $20 \%$ when compared to FORLs.

The both groups disagree that FORLs' academic career is negatively affected by financial factors. In fact, MORLs disagree about this perception more by $30 \%$ compared to FORLs' replies. This may be due to the stereotype about male's being held responsible for financial matters in the society.

In regards to (1) specialties requiring intensive workings hours and call duties are more suitable for males, (2) males being more successful in specialties requiring physical strength, MORLs agree that males certainly have an advantage over females. Even though FORLs approve males' physical advantage, they don't fully accept this fact based on their $30.1 \%$ "neutral" responses (Table 2).

In regards to (1) household chores are important burden for FORLs, and (2) concerns over work-life balance steer FORLs away from their academic careers, MORLs agree, including the "partially agree" responses, by $67.7 \%$ and

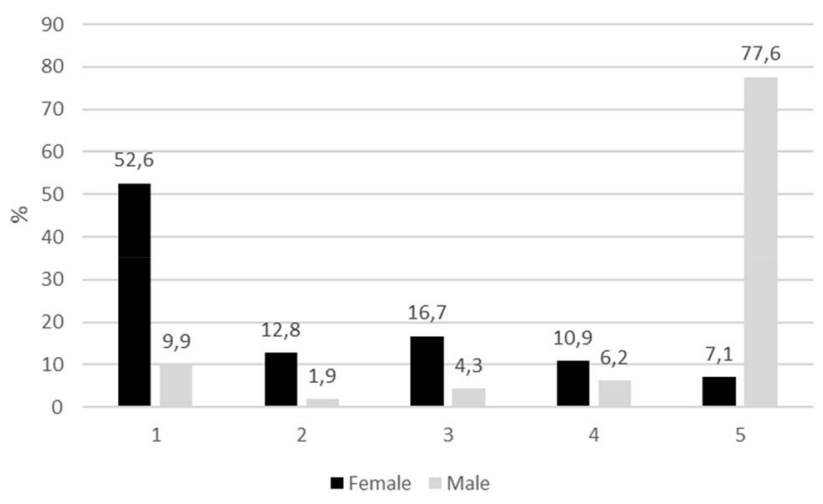

Fig. 2 Comparison of responses about taking men's words more into consideration in the department. Chi square: $165.29 \mathrm{P}=0.0001$. ( $1=$ disagree, 2 =partially disagree, $3=$ neutral, $4=$ partially agree, $5=$ agree)

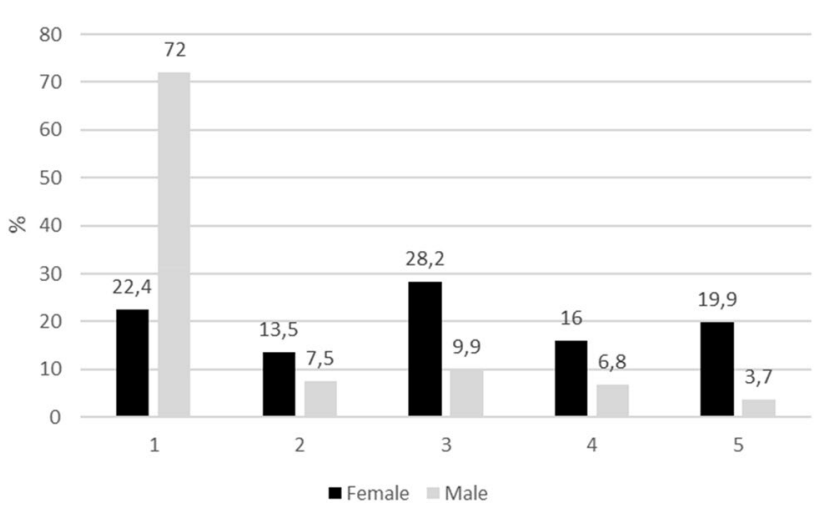

Fig. 3 Comparison of responses about MORLs being prioritized in pursuing an academic career. Chi square: $81.25 \mathrm{P}=0.001$. ( $1=$ disagree, $2=$ partially disagree, $3=$ neutral, $4=$ partially agree, $5=$ agree) 
$51.5 \%$ respectively. FORLs agree, including the "partially agree" responses, by $81.4 \%$ and $73.1 \%$, respectively. MORLs agree to the latter view about FORLs falling behind in their academic careers with some degree of ambiguity due to considerable number of replies on the disagreement scale side.

The responses of MORLs in regards to (1) patients taking MORLs more seriously and relying more on them, (2) patients' preference for their doctor's gender as a criterion, are generally scattered. Even though both MORLs and FORLs mostly agree on patients having confidence to MORLs and their preference for male surgeons, there is a noticeable divergence in the higher numbers of neutral answers of FORLs and the higher numbers in MORLs' disagreement (Table 2). As a matter of fact, patients' gender preference may differ depending on subspecialty; for example, head and neck oncology patients prefer males, while females are more preferred in pediatric otolaryngology [18]. On contrary, potential impact of physician's gender on patients' preference is not demonstrated in a study by Tracy LF et al. [19].

The limitation of our current study is the lesser number of MORLs' participation in spite of sending out the survey to quite a large sample group. This may be an indication of either unwillingness of MORLs to take part of a survey about gender discrimination or total lack of their interests about this issue. Thus, the results of this study may fall short in reflecting the views of MORLs in much wider range.

\section{Conclusion}

MORLs do not usually have any confrontation with FORLs in regards to the roles of women in the society such as their motherhood role. On the other hand, MORLs show rather a contradiction on their perception towards the gender discrimination mainly in achieving career goals by FORLs such as growing in the profession and holding managing roles. When the views of the both gender groups are compared, MORLs don't seem to fully acknowledge FORLs' gender discrimination experience.

Acknowledgement The authors thank to Emrah Can, Ayse Sibel Turkum, Prof and Orhan Yilmaz, Prof. for their invaluable support to this study.

Funding None.

\section{References}

1. Shannon G, Jansen M, Williams K, Caceres C, Motta A, Odhiamba A, Eleveld A, Monnell J (2019) Gender equality in science, medicine and global health: where are we at and why does it matter? Lancet 393(10171):560-569. https://doi.org/10.1016/ S0140-6836(18)33135-0

2. Eyigor H, Can IH, Incesulu A, Senol Y (2020) Women in otolaryngology in Turkey: insight of gender equalty, career development and work-life balance. Am J Otolaryngol 41:102305. https ://doi.org/10.1016/j.amjoto.2019.102305

3. Okafor S, Tibbetts K, Shah G, Tillman B, Agan A, Haldermann AA (2020) Is the gender gap closing in otolaryngology subspecialities? an analysis of research productivity. Laryngoscope 130(5):1144-1150. https://doi.org/10.1002/lary.28189

4. Bernardi K, Shah P, Lyons NB, Olavarria OA, Alawadi ZM, Leal IM, Holihan JL, Bass BL, Jakey CE, Kao LS, Ko TC, Kuo PC, Loor MM, Zheng F, Liang MK (2020) Perceptions on gender disparity in surgery and surgical leadership: a multicenter mixed method study. Surgery 167(4):743-750. https:// doi.org/10.1016/j.surg.2019.12.004

5. Cochran A, Houschild T, Elder WB, Neumayer LA, Brasel KJ, Crandall ML (2013) Perceived gender based barriers to careers in academic surgery. Am J Surg 206(2):263-268. https://doi. org/10.1016/j.amjsurg.2012.07.044

6. Tang AL, Millar A, Hauff S, Myer CM, Tahiar V, Howell JR, Mark JR (2019) Maternity and paternity leave in otolaryngology residency training in the United States. Laryngoscope 129(5):1093-1099. https://doi.org/10.1002/lary.27328

7. Alyono JC, Jackler JK, Chandrasekhar SS (2018) Women of the American otolaryngologic society. Otol Neurotol 39:S69-S80. https://doi.org/10.1097/MAO.0000000000001707

8. Choi SS, Miller RH (2012) Women otolaryngologist representation in speciality society membership and leadership positions. Laryngoscope 122:2428-2433. https://doi.org/10.1002/ lary. 23566

9. Grandis JR, Gooding WE, Zamboni BA, Wagener MM, Drenning SD, Miller L, Doyle KJ, Mackinnon SE, Wagner RL (2004) The gender gap in a surgical subspeciality. analysis of career and lifestyle factors. Arch Otolaryngol Head Neck Surg 130:695-702. https://doi.org/10.1001/archotol.130.6.695

10. Connolly S, Holdcroft A (2009) The pay gap for women in medicine and academic medicine. Women Med Fed, BMA reports

11. Jena AB, Olenski AR, Blumenthal DM (2016) Sex differences of physician salary in US public medical schools. JAMA Intern Med 176(9):1294-1304. https://doi.org/10.1001/jamaintern med.2016.3284

12. Baqi S, Albalbeesi A, Iftikhar S, Baig-Ansari N, Alanazi M, Alanazi A (2017) Perceptions of gender equality, work environment, support and social issues for women doctors at a university hospital in Riyadh. PLoS ONE 12(10):e0186896. https://doi. org/10.1371/journal.pone.0186896

13. Dermody SM, Litvack JR, Randall JA, Malekzadeh S, Maxwell JH (2019) Compensations of otolaryngologists in the veterans health administration: is there a gender gap? The Laryngoscope 129(1):113-118. https://doi.org/10.1002/lary.27311

14. Gonzalez JG, Forcen P, Sanchez MJ (2019) Men and women differ in their perception of gender bias in research institutions. PLoS ONE 14(12):e0225763. https://doi.org/10.1371/journ al.pone. 0225763

15. Handley IM, Brown ER, Moss-Racusin CA, Smith JL (2015) Quality of evidence revealing subtle gender biases in science is in the eye of the beholder. PNAS 112(43):13201-13206. https:// doi.org/10.1073/pnas.1510649112

16. Roter DL, Hall JA (2004) Physician gender and patient centered communication: a critical review of ampirical research. Annu Rev Public Health 25:407-519. https://doi.org/10.1146/annurev.publh ealth.25.101802.123134

17. Tsugama Y, Jena AB, Figueroa JF, Orav J, Blumenthal DM, Jha AK (2017) Comparison of hospital mortality and readmission rates for medicare patients treated by male versus 
female physician. JAMA Intern Med 177:206-213. https://doi. org/10.1001/jamainternmed.2016.7875

18. Chitguppi C, Brar T (2018) Do otolaryngology patients show gender preference when choosing a surgeon? a qualitative and quantitative analysis. Int Arch Otorhinolaryngol 22:404-407. https:// doi.org/10.1055/s-0038-1641165

19. Tracy LF, Jabbour N, Rubin BR, Sobin LB, Lawlor CM, Basa KC, Levi JR, Tracy JC (2019) Satisfaction in academic otolaryngology: do physician demographics impact press Ganey survey scores? Laryngoscope. https://doi.org/10.1002/lary.28335

Publisher's Note Springer Nature remains neutral with regard to jurisdictional claims in published maps and institutional affiliations. 